\title{
Experimental Investigation of Sugarcane Bagasse Ash Concrete Under Sodium Hydroxide Solution
}

\author{
Sachin Mulay, , , Gaurang Vesmawala', Yogesh Patil', Vikas Gholap ${ }^{2}$ \\ ${ }^{1}$ Applied Mechanics Department, SardarVallabhbhai National Institute of Technology, Surat, Gujarat, India \\ ${ }^{2}$ Department of Civil Engineering, Pravara Rural Engineering College, Loni, Maharashtra, India
}

\section{Email address:}

sachin_mulayce@yahoo.com (S. Mulay),grv22@yahoo.com(G. Vesmawala), chipatil@yahoo.com (Y.Patil), vicksgholap@gmail.com (V. Gholap)

*Corresponding author

\section{To cite this article:}

Sachin Mulay, Gaurang Vesmawala, Yogesh Patil, Vikas Gholap. Experimental Investigation of Sugarcane Bagasse Ash Concrete Under Sodium Hydroxide Solution. American Journal of Civil Engineering. Vol. 5, No. 1, 2017, pp. 1-8. doi: 10.11648/j.ajce.20170501.11

Received: October 21, 2016; Accepted: October 29, 2016; Published: November 23, 2016

\begin{abstract}
Sugarcane is one of the main cash crop grown in around 115 countries. The waste produced after its use as raw material is dumped on open lands. Detail estimation of sugarcane bagasse ash (SCBA) production on basis of sugarcane production all over as well as mainly in India is carried out in this study. Use of SCBA as a supplementary cementitious material adds sustainability to concrete by reducing the $\mathrm{CO}_{2}$ emission during cement production. The positive effects of SCBA as a partial replacement of cement on the mechanical properties of concrete are recognized through different researches; however, the overall improvement depends on the durability properties of SCBA in cementitious medium. In this study, durability properties of conventional concrete utilizing SCBA sourced from sugar factory site have been investigated. Concrete mixtures with SCBA content ranging from $0 \%$ to $30 \%$ of total binder were used. The compressive strength, ultrasonic pulse velocity and loss in weight of the concrete specimens were determined after exposure to sodium hydroxide solution. The reactivity of alkali with mixes containing SCBA in terms of expansion was determined by accelerated as well as Indian standard test method. The results demonstrated that incorporation of SCBA as partial replacement of cement improved the resistance to alkali attack on concrete. The SCBA in cement aggregate mix showed reduction in expansion proving the effectiveness of waste SCBA inclusion in cementitious medium.
\end{abstract}

Keywords: Bagasse Ash, Cement Concrete, Alkali Attack, Durability

\section{Introduction}

Concrete has become a part and partial of overall development in terms of social and economic aspects. Increase in concrete consumption is forcing in increase of cement production. Cement manufacturing hampers the environment in respect of $\mathrm{CO}_{2}$ emission, depletion of natural resources which has become a challenge in front of researchers. Similarly many developing and developed countries has regularized use of pozzolanic materials in portland cement on account of achieving control on environmental issues and also improving quality of concrete mainly the durability apsect.

Utilization of agricultural, industrial and agro- industrial by-products in concrete production has become an attractive area to the researchers worldwide. Utilization of such wastes as cement replacement materials also as mineral admixture can reduce the cost of concrete and also minimize the negative environmental effects associated with the disposal of these wastes. Silica fume, rice husk ash, fly ash, metakaolin and ground granulated blast furnace slag are well established pozzolans because of high silica contents in their chemical composition [1-5].

The calcium hydroxide (unfavourable product from the cement hydration) released during the hydration of portland cement reacts with the silica content present in the pozzolans and water to form additional calcium silicate hydrate which is responsible for the improvement in strength of cementitious mediums [6]. Secondary calcium silicate hydrate formed helps in improving the overall durability aspect. The economy of a structure which is mainly dependent on the life of structure is observed to be increasing 
with inclusion of pozzolanic materials.

Sugarcane crop is grown worldwide for producing sugar, ethanol and many more. The bagasse a waste material after extracting juice in sugar industry after drying is usually used as a fuel for boilers in the sugar mills and alcohol factories which produce high amounts of ash annually. With increasing cost of natural gas, electricity and fuel oil, dried bagasse with high calorific value has been used as the principal fuel in sugar factory boilers to produce heat and in cogeneration plants to produce electric power.

Sugarcane Bagasse Ash (SCBA) is usually obtained under uncontrolled burning conditions in boilers, thus the ash may contain black particles due to the presence of carbon and crystalline silica when burning occurs under high temperature (above $800^{\circ} \mathrm{C}$ ) or for a prolonged time. The quality of the ash can be improved by controlling parameters such as temperature, rate of heating. When the bagasse is burnt under controlled conditions it may produce ash with high amorphous silica, which has the pozzolanic properties [7].

Study of using SCBA as a pozzolanic material is not wellknown and its uses are limited and most of SCBA is disposed in the landfills, and "only a few studies have been reported on the use of SCBA as a pozzolanic material in respect of the cement medium" $[8,9]$. There is a continuous increase in the production of sugar and ethanol worldwide using sugarcane as raw material. Utilization of such agro-industrial byproducts as cement replacement materials in cementitious system (i.e. mortar and concrete) will not only save the environment; but also will reduce the cement production and consequently the high energy consumption, reduce the $\mathrm{CO}_{2}$ emission, reducing overall cost of concrete.

The effect of alkalis on various properties of cement paste, mortar and concrete, in form of alkali-silica (reactive aggregates) is like cancer if untreated hampers the durability aspect in broader terms the life of structures. It has been observed from previous research that high alkali content in cementitious medium is more susceptible to expansion it causes [10].

A number of experimental study show that the higher the alkali content in cement, the lower the ultimate strength of corresponding specimen, in whatever the manner this alkali content is achieved (i.e. high alkali clinkers or external addition of alkali sulphates, carbonates or hydroxides) the result are less w.r.t ultimate strength of sample.

Where the effect of alkali silicate reaction on concrete strength is investigated in laboratory by comparison between low alkali/ non expansive and high alkali/ expansive concretes made with the same reactive aggregates but where the high alkali/ expansive concrete is obtained by adding sodium hydroxide to the mixture of water which is quite common, it must be recalled that the observed reduction of strength are partly due to the higher alkali content by itself [11]. Utilization of SCBA as cement replacement material at wide spread level, it is important to take into account durability aspect of the cementitious medium exposed to sodium hydroxide.

The present work deals with estimation of SCBA based on the production of sugarcane worldwide as well as in India. Based on larger quantity of waste ash available worldwide as well as mainly in India, an experimentation was carried out to understand the effect of SCBA as cement replacement material on concrete so as to evaluate the performance when exposed to sodium hydroxide solution.

\section{Sugarcane Production and Estimation of Bagasse Ash}

To use SCBA at large extent in cementitious medium the knowledge and estimation of sugarcane production as well as SCBA coming out from factories is important. The detailed estimation of ash content based on sugarcane produced is carried out in this study. The present study is based on the statistical data available of the sugaracane all over the world and mainly in different states in India.

\subsection{World Sugarcane Production}

Sugarcane is a cash crop grown in many countries all over the world. To undergo detail estimation of SCBA the quantity of sugarcane production in different countries is obtained. As per the FAOSTAT, sugarcane produced in different countries is as shown in table 1 [12]. It is used mainly for making sugar, ethanol, alcohol and many more in different countries. In India major part of sugarcane is mainly used for making gur and khandsari whereas the remaining for sugar and alcohol production.

Table 1. Main sugarcane producing countries as per FAOSTAT for year 2010-11.

\begin{tabular}{lll}
\hline Ranking & Country & Sugarcane Production (tonnes) \\
\hline 1. & Brazil & $734,006,000$ \\
2. & India & $342,382,000$ \\
3. & China & $115,123,560$ \\
4. & Thailand & $95,950,400$ \\
5. & Pakistan & $55,308,500$ \\
6. & Mexico & $49,735,300$ \\
7. & Philippines & $34,000,000$ \\
8. & USA & $26,655,800$ \\
9. & Australia & $25,181,800$ \\
10. & Argentina & $25,000,000$ \\
11. & Colombia & $22,727,800$ \\
12. & Cuba & $15,800,000$ \\
& Others & $308,350,970$ \\
& Total & $1,850,222,130$ \\
\hline
\end{tabular}

At present, 115 countries of the world cultivate sugarcane mainly for sugar and ethanol production. As per the statistics about 1850 million tonnes of sugarcane is grown all over and used for different purposes. The three largest sugarcane growers in terms of production are Brazil, India and China. About $50 \%$ of the total production of sugarcane is found to be concentrated mainly in Brazil, India and China.

India is a second largest producer of sugarcane as well as consumer of the sugar in the world. About 342 million tonnes of sugarcane was produced, which was nearly 18.5 percent of the total sugarcane production of the world. This directly shows a larger production of waste after use of sugarcane as 
raw material. Production of larger quantity of sugarcane is showing a scope to researcher towards waste management.

\subsection{World Bagasse Ash Estimation}

Extraction of juice through sugarcane crushing gives out about $25 \%$ to $30 \%$ of wet bagasse. Bagasse in wet condition contains about $40 \%$ to $50 \%$ of moisture. Sugarcane bagasse is used as a raw material for manufacturing of paper, also used as fuel to generate steam in mills and in cogeneration plants. Burning of bagasse gives out about 3\% to $5 \%$ of ash which is a waste material dumped on open lands creating pollution.

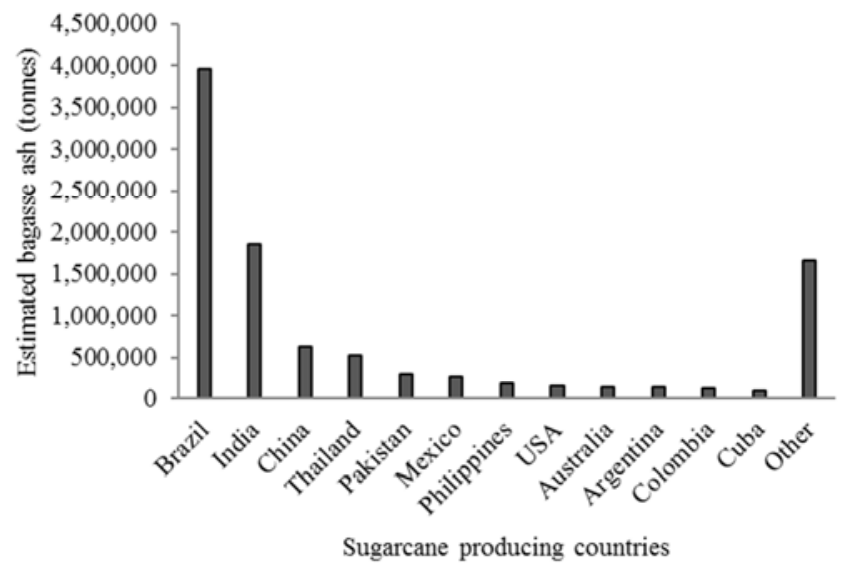

Figure 1. Sugarcane bagasse ash estimate for different countries.

Considering production of all sugarcane producing countries, SCBA waste is found out to be about 10 million tonnes as highlighted in fig. 1. Such a large quantity of waste coming out from sugar industries is creating a challenge in front of researchers for proper waste management.

\subsection{Sugarcane Production: India}

Statistics of 2010-11 as per ICAR, Sugarcane Breeding Institute, Coimbatore, India of sugarcane production highlights the increase in production by about 10 times in last 80 years as shown in fig. 2 [11]. With increase in need of sugaracane, in future the sugarcane production is expected to rise based on the topograhical and climatic conditions.

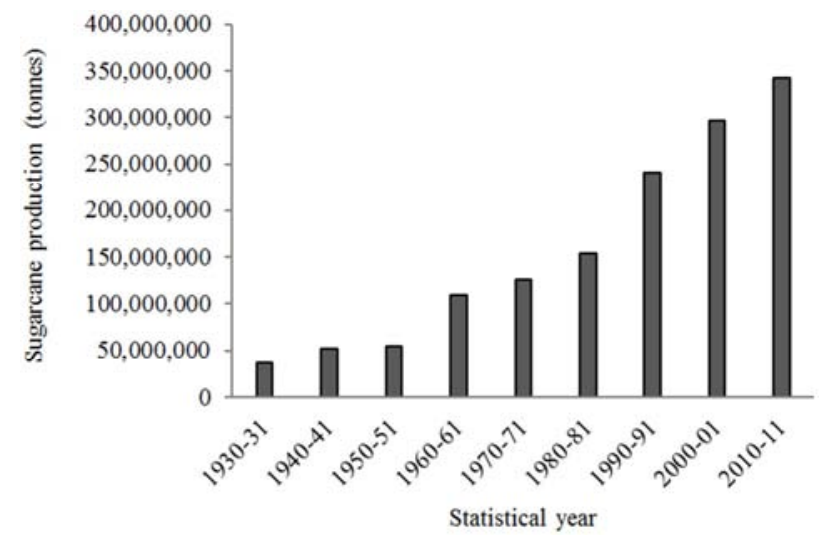

Figure 2. Sugarcane production in India as per ICAR for different statistical years.
In India, there are two distinct zones for sugarcane cultivation, tropical-south and subtropical north. Subtropical north while comprising 60 per cent of total cane area contributes only 48 per cent to total cane and 37 per cent to total white sugar production in the country. The state wise production of sugarcane in India is shown in table 2, so as to understand the overall scenario of SCBA in India.

Table 2. Main sugarcane producing states in India as per ICAR for year 2010-11.

\begin{tabular}{lll}
\hline Ranking & States & Sugarcane Production (tonnes) \\
\hline 1 & Uttar Pradesh & $120,555,000$ \\
2 & Maharashtra & $78,838,000$ \\
3 & Karnataka & $37,595,000$ \\
4 & Tamil Nadu & $34,292,000$ \\
5 & Bihar & $15,000,000$ \\
6 & Andhra Pradesh & $14,784,000$ \\
7 & Gujarat & $14,240,000$ \\
8 & Haryana & $5,987,000$ \\
9 & Punjab & $4,170,000$ \\
10 & Madhya Pradesh & $2,667,000$ \\
11 & Orissa & 903,000 \\
& Others & $13,351,000$ \\
& Total & $342,382,000$ \\
\hline
\end{tabular}

Uttar Pradesh and Maharashtra produced about 58 percent of sugarcane compared to total production of India during 2010-11, which was nearly 11 per cent of the total sugarcane production of the world. Maharashtra is second largest producer of sugarcane and which is about 23 percent compared to total production. The present study focuses on use of SCBA as cement replacement material dumped on open lands produced in Pravara sugar factory, Maharashtra, India.

Fig. 3 highlights the SCBA estimated based on the sugarcane production in India in different states.

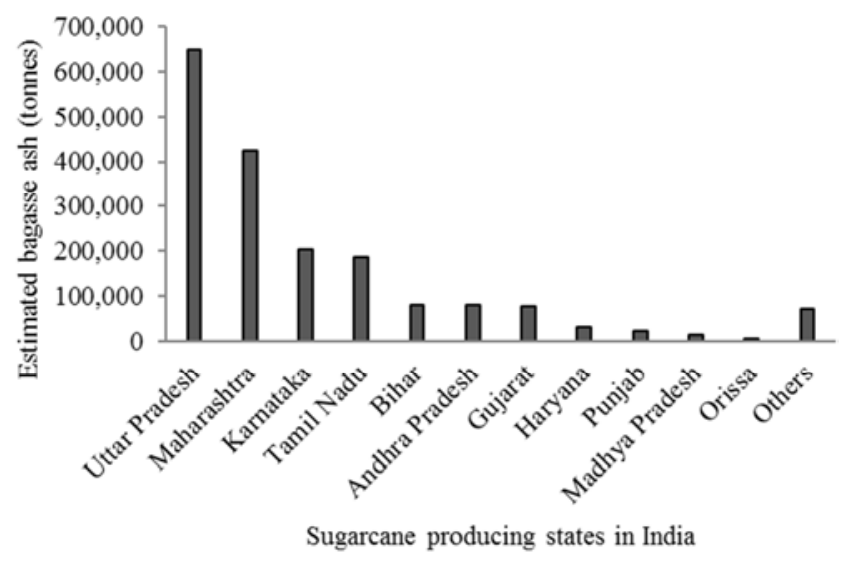

Figure 3. Sugarcane bagasse ash estimated for different states in India.

With the increasing demand of sugar and the positive approach towards ethanol production is creating a wide scope and challenge for utilization of waste SCBA in India. Proper utilization of about 1.85 million tonnes of sugarcane SCBA in cementitious system is a challenge in front of researchers. Use of SCBA as cement replacement material can be effective for reducing environment pollution with reduction in cement consumption. 


\section{Material Properties}

\subsection{Cement (OPC)}

To check the effect of replacing cement by SCBA, study of physical, chemical and mechanicalproperties of cement is important. Ultra-Tech 53 Grade OPC is used for the work with the properties checked in Dirk India Ltd. Research Laboratory, Nasik. This type of cement is commonly used in India. Detail properties of cement used for this study are shown in tables 3, 4 and 5 .

\subsection{River Sand}

Locally available sand, from Pravara river was used as fine aggregate confirming to IS 383:1970 [14]. The silt content present in sand was found to be $1 \%$. The detail physical properties of sand are as shown in table 6 .

\subsection{Coarse Aggregate}

Locally available crushed basalt stone with nominal maximum 20mm size aggregates confirming to IS 383:1970 were used in present experimentation work. The properties of coarse aggregates are shown in table 6.

Table 3. Physical properties of OPC.

\begin{tabular}{lllll}
\hline Type & Specific Gravity $\left(\mathbf{g m} / \mathbf{c m}^{\mathbf{3}}\right)$ & Mean grain size $(\boldsymbol{\mu m})$ & Fineness passing $\mathbf{4 5} \boldsymbol{\mu m}(\mathbf{\%})$ & Specific surface $\operatorname{area}\left(\mathbf{m}^{2} / \mathbf{k g}\right)$ \\
\hline Ultratech-53 OPC & 3.1 & 21.50 & 87 & 313 \\
\hline
\end{tabular}

Table 4. Chemical properties of OPC.

\begin{tabular}{|c|c|c|c|c|c|c|c|c|c|}
\hline Type & $\mathrm{SiO}_{2}$ & $\mathbf{A l}_{2} \mathbf{O}_{3}$ & $\mathrm{Fe}_{2} \mathrm{O}_{3}$ & $\mathrm{CaO}$ & MgO & $\mathrm{SO}_{3}$ & $\mathrm{Na}_{2} \mathrm{O}$ & $\mathbf{K}_{2} \mathbf{O}$ & LOI \\
\hline Ultratech-53 & 20.12 & 5.76 & 3.39 & 63.70 & 0.29 & 2.68 & 0.34 & 0.79 & 1.47 \\
\hline
\end{tabular}

Table 5. Mechanical properties of OPC.

\begin{tabular}{llllll}
\hline \multirow{2}{*}{ Standard Consistency (\%) } & \multirow{2}{*}{ Initial Setting Time (min) } & \multirow{2}{*}{ Final Setting Time (min) } & $\begin{array}{l}\text { Soundness } \\
(\mathbf{m m})\end{array}$ & \multicolumn{2}{l}{ Average Compressive Strength $\left(\mathbf{N} / \mathbf{m m}^{2}\right)$} \\
\cline { 4 - 7 } & & 308 & $\mathbf{3}$ days & $\mathbf{7}$ days & $\mathbf{2 8}$ days \\
\hline 29 & 180 & 1.00 & 31.67 & 39.35 \\
\hline
\end{tabular}

Table 6. Physical properties of sand and coarse aggregate.

\begin{tabular}{llll}
\hline Sr. No & Property & Sand & Coarse Aggregate \\
\hline 1. & Particle Shape, Size & Round, $<4.75 \mathrm{~mm}$ & Crushed angular, 20 mm \\
2. & Fineness Modulus & 3.45 & 6.78 \\
3. & Silt content (\%) & 1.0 & Nil \\
4. & Specific Gravity & 2.60 & 2.77 \\
5. & Surface moisture & Nil & Nil \\
6. & Water Absorption $(\%)$ & 1.65 & 1.00 \\
\hline
\end{tabular}

\subsection{Water}

In the present experimental work, tap water suitable for drinking was used for concreting and curing. The $\mathrm{pH}$ of water used for the present study was found out by $\mathrm{pH}$ meter. It was observed to be 6.8 .

\subsection{Sugarcane Bagasse Ash}

SCBA used as cement replacement material for present study was collected from open lands near sugar factory in Maharashtra, India. Factory ash with high carbon content was burnt at controlled temperature $650^{\circ} \mathrm{C}$ for 1 hour and was ground before use [15]. SCBA was used as cement replacement material in concrete at replacement levels of 0 , $5,10,15,20,25$ and $30 \%$. The present study aims at checking the effect of replacing cement by SCBA on properties of concrete exposed to sodium hydroxide. The silicious content in SCBA was found to be $72.5 \%$ and its fineness passing $45 \mu \mathrm{m}$ was found to be $58 \%$ and that passing $90 \mu \mathrm{m}$ was above $95 \%$.

\section{Experimentation Procedure}

Concrete with and without SCBA was exposed to water with $5 \%$ concentration of sodium hydroxide and different tests were conducted to determine effectiveness of ash inclusion in cement medium. The process to conduct different tests to understand the same is as explained below.

\subsection{Casting of Concrete Cubes}

Concrete mix design was done as per IS 10262-2009 is shown in table 7 [16]. The cube compressive strength at end of 28 days of normal water curing was obtained to be 29 $\mathrm{N} / \mathrm{mm}^{2}$. Cement was replaced by SCBA at $0,5,10,15,20,25$ and $30 \%$ by weight. Cubes moulds with inner dimension $150 \mathrm{~mm} \times 150 \mathrm{~mm} \times 150 \mathrm{~mm}$ were filled with concrete of each mix and fully compacted. For each test and mix conditions three cubes were casted. The concrete cubes in moulds were kept on platform free from vibration under normal room temperature for setting. 


\subsection{Curing and Testing of Concrete Cubes}

Concrete cubes were demoulded after $24 \mathrm{hrs}$ of casting and were immersed in normal water for curing. After 28 days and 56 days water curing the compressive strength was determined.

\subsection{Compressive Strength Test}

The concrete cubes were tested under uniaxial compression testing machine with $2000 \mathrm{KN}$ capacity as per IS 516-1959 at required curing and exposure period [17]. Three cubes of each mix and curing condition were tested and average of it is presented in this study. The crushing load $(\mathrm{KN})$ was obtained and the strength was determined with respect to the surface area $\left(\mathrm{mm}^{2}\right)$ as load per unit area in $\mathrm{N} / \mathrm{mm}^{2}$.

\subsection{Weight Loss}

Concrete cubes after water curing were removed and allowed to dry naturally for 3 days and weighed termed as weight prior to immersion $\left(\mathrm{w}_{1}\right)$ and similarly cubes exposed to alkali attack were taken out of solution and allowed to dry naturally for 3 days and weighed as weight after immersion $\left(\mathrm{w}_{2}\right)$. The difference between these weights determined the loss in weight as given by the equation below,

$$
\text { Weight loss }(\%)=[\mathrm{w} 2-\mathrm{w} 1]^{*} 100 / \mathrm{w} 1
$$

\subsection{Ultrasonic Pulse Velocity (UPV)}

The UPV test was conducted on naturally dried cube specimens after different exposure period as per IS 133111992 and are presented in the study [18]. The pulse velocity (v) was determined by using direct transmission wave propogation method by using two probes. One probe as transmitter and the other as receiver. The time ( $\mathrm{t}$ ) required for wave to propogate through length of cube specimen (L) was determined. The pulse velocity $(\mathrm{m} / \mathrm{s})$ was determined as the specimen wave propogation length per unit time. Fig. 4 shows diagram to understand the detail set up used for carrying out the test. UPV test was conducted on cube specimens naturally dried after removing from the alkali solution.

\subsection{Chemical Attack}

To understand the effect of alkali exposure on concrete with different contents of SCBA, 56d normally cured concrete cube specimens were immersed in water with $5 \%$ sodium hydroxide. Compressive strength, UPV test and loss in weight was determined after $7 \mathrm{~d}, 28 \mathrm{~d}$ and $56 \mathrm{~d}$ of chemical exposure. Three cubes were tested for each condition and the average is presented in the study.

Table 7. Mix proportion for present experimentation.

\begin{tabular}{l|ll}
\hline Material & Proportionate weight & Weight in $\mathbf{K g} / \mathbf{m}^{\mathbf{3}}$ \\
\hline Cement & 1 & 420 \\
FA & 1.44 & 608 \\
CA & 2.79 & 1177 \\
W/C & 0.43 & 180.6 \\
\hline
\end{tabular}

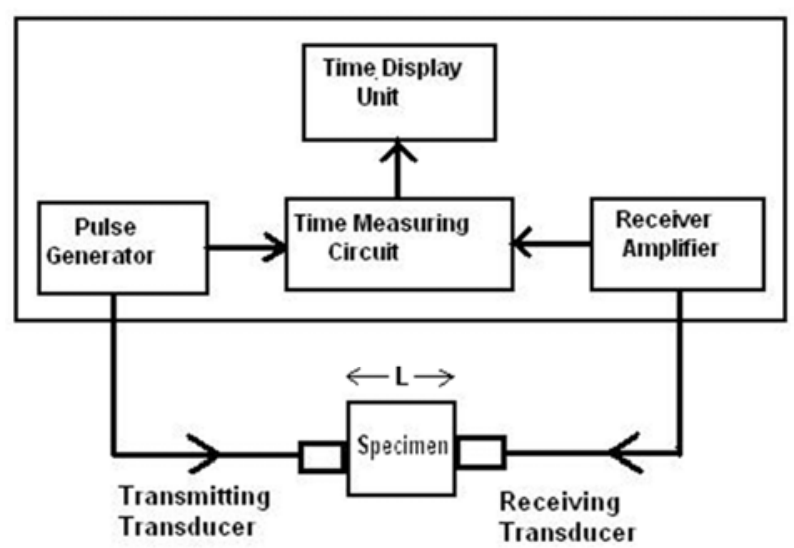

Figure 4. Schematic diagram of ultrasonic pulse velocity test set up.

\section{Expansion test}

The accelerated test method as well as method as per IS: 2386 (Part VII)-1963 to study reaction of alkali on reactive aggregate was used in the present experimentation work. Accelerated method adopted by Kishore, gives results much faster that is in 7 days compared to method adopted as per IS: 2386 (Part VII)-1963 were test continues much beyond 6 months $[10,19]$. Coarse aggregates were crushed and graded as per guidelines given in IS: 2386 table II, and six prisms specimens of each SCBA content of size $25 \mathrm{~mm}$ x $25 \mathrm{~mm}$ x $250 \mathrm{~mm}$ were casted by using cement and aggregates mixes as per mix design in table 6. Prism specimens were demoulded after 24 hours of casting. Three specimens were immersed in normal water for 24 hours and length of specimens was measured prior to immersion in 5\% sodium hydroxide mixed in water maintained at normal temperature. At the end of 6 months immersion period the expansion of specimens was measured and presented in this study

Remaining three specimens tested at accelerated rate were immersed in distilled water for 24 hours at $70^{\circ} \mathrm{C}$. The length of prism was measured before immersing the specimens in water solution with $5 \%$ sodium hydroxide maintained at $70^{\circ} \mathrm{C}$. The length of prism specimens was measured on every day till 7 days exposure to the sodium hydroxide solution. The expansion by both the methods helps to provide a test to understand potential of alkali reaction with the mix containing aggregates at accelerated as well as normal exposure conditions. The average of the three specimens is presented in this paper.

\section{Results and Discussion}

The test results for the experimentation work carried out to understand the behavior of SCBA in concrete exposed to alkali is presented as below.

\subsection{Weight Loss}

For water cured concrete, with increase in SCBA from $0 \%$ to $30 \%$,specimen weight was observed to be reducing at the 
end of 56d are shown in table 8. Fig. 5 shows the behavior of concrete with different SCBA content exposed to alkali for 7d, 28d and 56d. Exposure of concrete mixes to alkali attack showed overall reduction in weight at exposure period of $7 \mathrm{~d}$, $28 \mathrm{~d}$ and $56 \mathrm{~d}$ compared to $56 \mathrm{~d}$ weight of concrete specimens cured under water. The specimen weight exposed to alkali was observed to reduce at slower rate. The maximum loss in weight was observed with $0 \%$ and $30 \%$ SCBA content mixes for all alkali exposure period conditions. The minimum loss in weight was observed with $15 \%$ SCBA content at $7 \mathrm{~d}, 28 \mathrm{~d}$ and 56d exposure period.

For all exposure periods the loss in weight was observed to be decreasing with increase in SCBA content from $0 \%$ to $15 \%$, whereas above $15 \%$ SCBA content the weight was observed to be decreasing upto $30 \%$ SCBA content. The residue weight at 56d alkali exposure was found to be $94 \%$, $96 \%$ and $93 \%$ for $0 \%, 15 \%$ and $30 \%$ SCBA respectively. Inclusion of SCBA as cement replacement in concrete showed improvement in the results under alkali exposure condition.

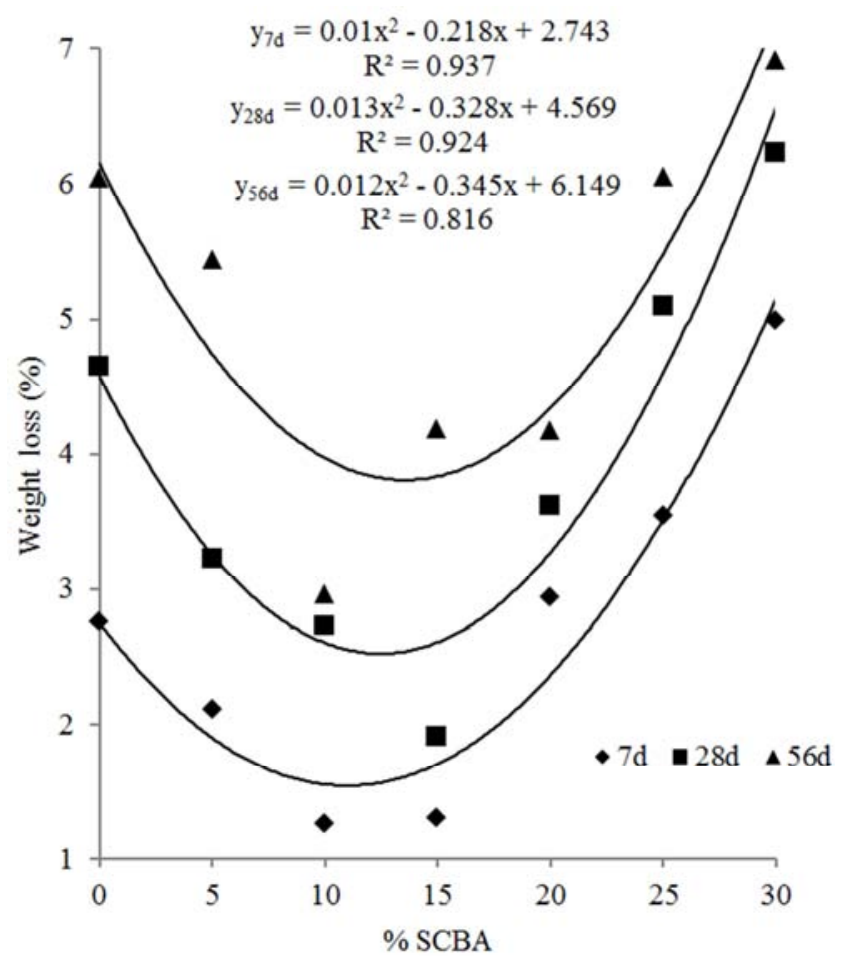

Figure 5. Effect of alkali attack on weight of concrete containing SCBA.

\subsection{Compressive Strength}

Fig. 6 shows the compressive strength of concrete with $0 \%$ to $30 \%$ SCBA cured under normal water for $28 \mathrm{~d}$ and $56 \mathrm{~d}$. Strength at $28 \mathrm{~d}$ was observed to be reducing with increase in SCBA content. At $56 \mathrm{~d}$ the strength was observed to be increasing with increase in SCBA upto $15 \%$ and above this content reduction in strength was found, highlighting the slower reactivity of SCBA during initial period. Compressive strength was found to be increasing by $21 \%$ for $15 \%$ SCBA specimen compared to concrete without SCBA at end of 56d.

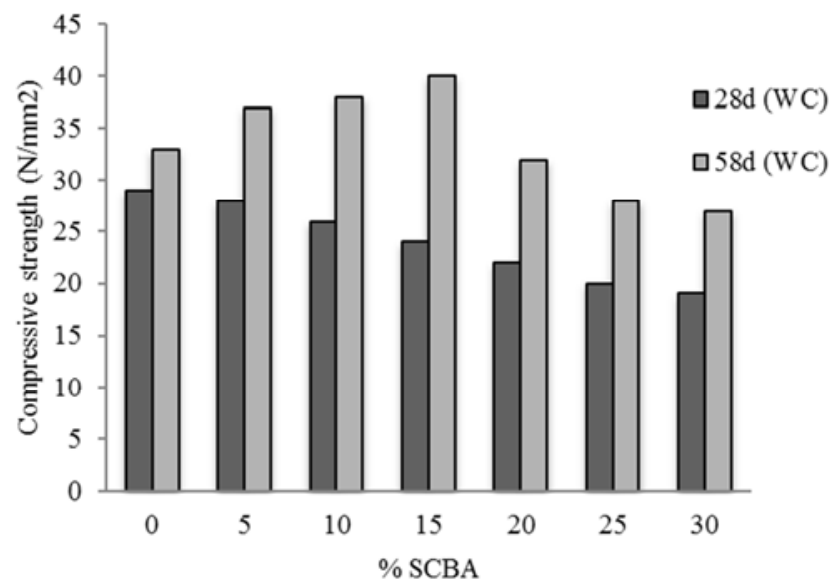

Figure 6. Effect of SCBA on compressive strength of concrete at $28 d$ and $56 d$ (WC-Normal water cured).

Fig. 7 highlights the compressive strength of concrete with $0 \%$ to $30 \%$ SCBA exposed to alkali attack for $7 \mathrm{~d}, 28 \mathrm{~d}$ and $56 \mathrm{~d}$. Overall strength of concrete with and without SCBA was observed to be reducing with increase in alkali solution exposure period as compared to strength of water cured concrete. Exposure of concrete specimens in present work to alkali attack showed maximum reduction in strength for mix with $0 \%$ and $30 \%$ SCBA content $(7 \mathrm{~d}-6 \%$ and $3 \%$; $28 \mathrm{~d}-8 \%$ and $11 \% ; 56 \mathrm{~d}-15 \%$ and $17 \%$ ) respectively. The minimum loss in strength due to alkali attack was observed with $15 \%$ SCBA concrete specimens. The reduction in compressive strength for $15 \%$ SCBA concrete specimens was determined to be $3 \%, 4 \%$ and $9 \%$ at end of $7 d, 28 d$ and $56 \mathrm{~d}$ alkali exposure.Effective use of SCBA as cement replacement material in concrete with optimum dosage of $15 \%$ can be considered from the present experimentation.

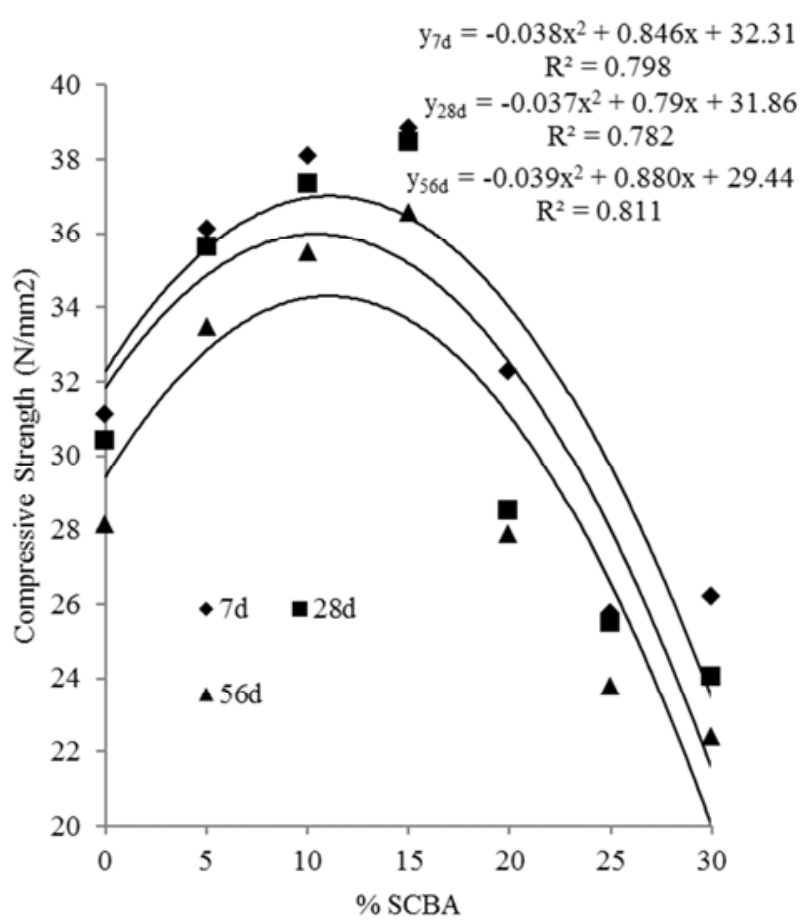

Figure 7. Effect of alkali attack on compressive strength of concrete containing SCBA. 
Table 8. Weight and UPV at 56 days water curing.

\begin{tabular}{lll}
\hline Mix (Cement + SCBA) & Weight $(\mathbf{g})$ & UPV $(\mathbf{m} / \mathbf{s})$ \\
\hline $100+0$ & 8640 & 4760 \\
$95+5$ & 8575 & 4853 \\
$90+10$ & 8511 & 4998 \\
$85+15$ & 8447 & 5298 \\
$80+20$ & 8383 & 4545 \\
$75+25$ & 8319 & 4188 \\
$70+30$ & 8255 & 4007 \\
\hline
\end{tabular}

\subsection{Ultrasonic Pulse Velocity}

Table 8 demonstrates the UPV results for different cement replacement conditions in concrete by SCBA cured under water for 56d. Pulse velocity values were observed to be increasing with increase in SCBA upto $15 \%$, whereas above this content velocity was found to be decreasing. As per IS 13311-1992 classification, concrete with $0 \%$ to $20 \%$ SCBA concrete can be considered to be excellent, whereas $25 \%$ and $30 \%$ SCBA concrete can be categorized as good. The compactness of concrete can be defined by higher velocity values.

Concrete specimens when exposed to alkali showed reduction in UPV results compared to values of specimens cured under water as shown in fig. 8. The maximum reduction in UPV during $7 \mathrm{~d}$ and $28 \mathrm{~d}$ exposure was found to be $9 \%$, whereas at $56 \mathrm{~d}$ the reduction was maximum with $0 \%$ SCBA concrete (i.e. 12\%). Concrete with 5\%, $10 \%$ and $15 \%$ can be categorized as excellent whereas other mixes as good, after being exposed to alkali attack.

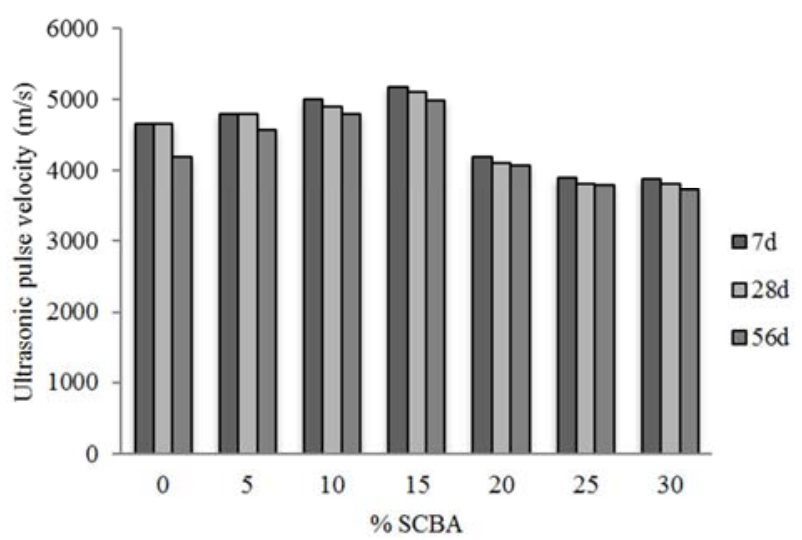

Figure 8. Effect of SCBA on Ultrasonic pulse velocity of concrete (WCNormal water cured).

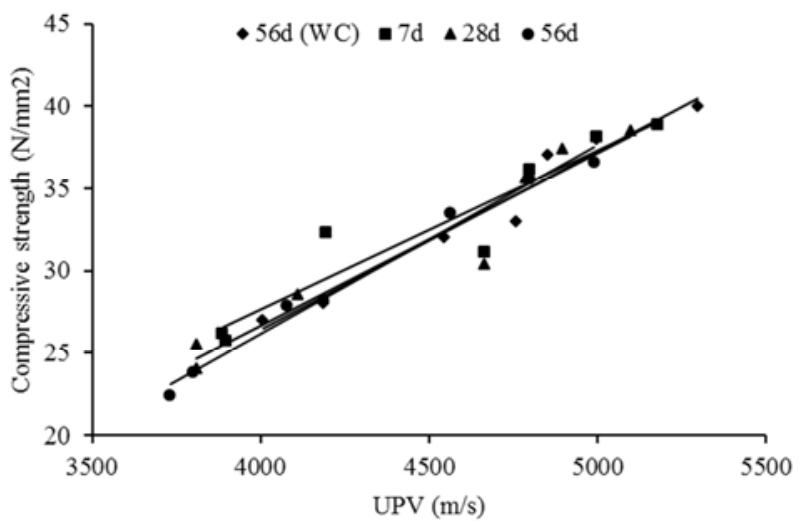

Figure 9. Relation between compressive strength and UPV.
Fig. 9 shows that the compressive strength and UPV values are analogous to each other. Relation developed between the compressive strength and UPV for different curing conditions is as shown below:

$$
\begin{gathered}
\mathrm{y}_{56(\mathrm{wc})}=0.010 \mathrm{x}-16.84\left(\mathrm{R}^{2}=0.960\right) \\
\mathrm{y}_{7 \mathrm{~d}}=0.009 \mathrm{x}-10.85\left(\mathrm{R}^{2}=0.893\right) \\
\mathrm{y}_{28 \mathrm{~d}}=0.010 \mathrm{x}-15.25\left(\mathrm{R}^{2}=0.929\right) \\
\mathrm{y}_{56 \mathrm{~d}}=0.011 \mathrm{x}-19.43\left(\mathrm{R}^{2}=0.985\right)
\end{gathered}
$$

The relations can be used to predict the destructive strength parameter only knowing the UPV values on field for evaluation of alkali effect under the considered properties and conditions.

\subsection{Expansion Test Results}

The results for the prism specimens made with different mixes exposed to sodium hydroxide solution at $7 \mathrm{~d}$ accelerated test and method as per IS code are shown in fig. 10. The exposure to alkali solution showed overall expansion in all the prism specimens. The maximum expansion of prism specimens was noted as for mix with $30 \%$ SCBA content.

The expansion of prism specimens was observed to be reducing with increase in SCBA content from $0 \%$ to $15 \%$, whereas above $15 \%$ content the expansion was observed to be increasing. Alkali content mainly responsible for alkali aggregate reaction showed reduction in the reactivity mainly due to the SCBA as the variable content in form of reduction in expansion rate. $15 \%$ SCBA content in mixture showed improvement in resistance against alkali silica reaction. Mix with $15 \%$ SCBA showed reduction in expansion by $31 \%$ under accelerated test condition, whereas for longer duration test the expansion was observed to be $24 \%$ lesser compared to mix without SCBA. The expansion due to alkali reactivity with $30 \%$ SCBA mix was found to be higher by about $11 \%$ compared to mix without SCBA exposed to alkali for both test conditions.

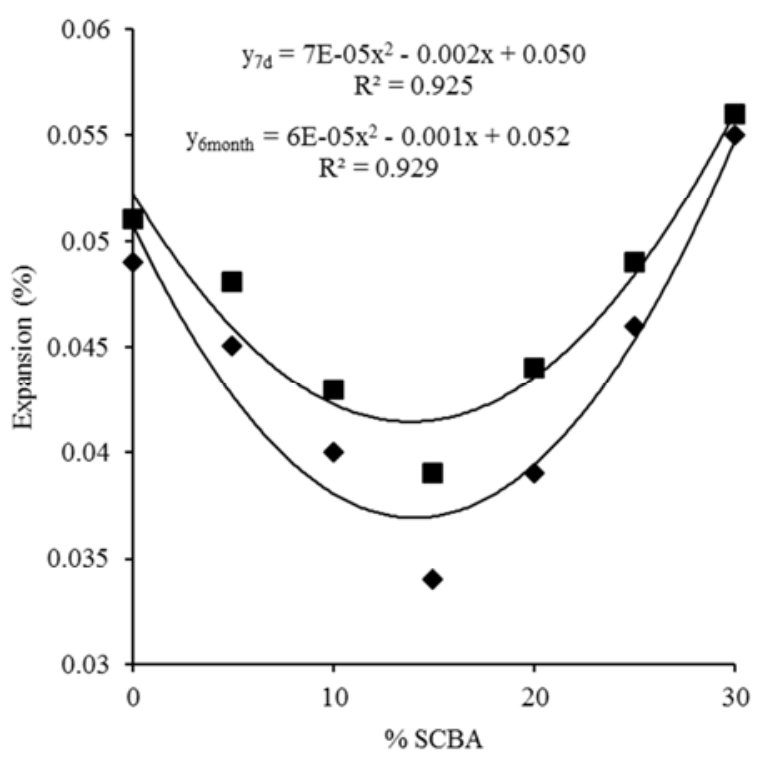

Figure 10. Effect of SCBA on expansion of prism specimens at $7 d$ and 6 months alkali exposure. 


\section{Conclusions}

The effect of bagasse ash waste as cement replacement material in concrete showed improvement in results under normal water curing proving the effectiveness towards sustainable development. The following conclusion were derived from the experimental outcome of concrete with bagasse ash under sodium hydroxide solution,

- The reduction in weight due to sodium hydroxide exposure was observed to be decreasing with increase in bagasse ash content from 0 to $15 \%$ above which reduction rate increased at different exposure periods.

- Compressive strength and ultrasonic pulse velocity values were determined to be higher for mix with $15 \%$ bagasse ash content at all alkali exposure periods.

- Inclusion of bagasse ash in cement aggregate mix showed improvement in resistance to alkali silica reaction

- Optimal utilisation of SCBA in concrete for maximum output was derived to be $15 \%$.

\section{References}

[1] Z. Zhang, B. Zhang, and P. Yan, "Comparative study of effect of raw and densified silica fume in the paste, mortar and concrete," Construction and Building Materials, vol. 105, pp. 82-93, February 2016.

[2] K. Park, S. Kwon, and X. Wang, "Analysis of the effects of rice husk ash on the hydration of cementitious materials," Construction and Building Materials, vol. 105, pp. 196-205, February 2016.

[3] N. Chousidis, E. Rakanta, I. Ioannou, and G. Batis, "Mechanical properties and performance of reinforced concrete containing fly ash," Construction and Building Materials, vol. 101 (part 1), pp. 810-817, December 2015.

[4] Q. Li, H. Geng, Z. Shui, and Y. Huang, "Effect of metakaolin addition and sea water mixing on the properties and hydration of concrete," Applied Clay Science, vol. 115, pp. 51-60, October 2015.

[5] M. O'Connell, C. McNally, and M. Richardson, "Peformance of concrete incorporating GGBS in aggressive wastewater environments," Construction and Building Materials, vol. 27(1), pp. 368-374, February 2012.

[6] S. T. Lee, H. Y. Moon, R. D. Hooton, and J. P. Kim, "Effect of solution concentrations and replacement levels of metakaolin on the resistance of mortars exposed to magnesium sulfate solutions," Cement and Concrete Research, vol. 35(7), pp. 1314-1323, July 2005.

[7] M. Frias, E. Villar, and H. Savastano,"Brazilian sugar cane bagasse ashes from the cogeneration industry as active pozzolans for cement manufacture," Cement and Concrete Composites, vol. 33(4), pp. 490-496, April 2011.

[8] A. Bahurudeen, A. V. Marckson, A. Kishore, and M. Santhanam,"Development of sugarcane bagasse ash based Portland pozzolana cement and evaluation of compatibility with superplasticizers," Construction and Building Materials, vol. 68, pp. 465-475, October 2014.

[9] S. Rukzon, and P. Chindaprasirt, "Utilization of bagasse ash in high-strength concrete," Materials and Design, vol. 34, pp. 4550, February 2012.

[10] K. Kishore, "Alkali-silica reaction in concrete,"Irrigation and Power Journal, vol. 49(4), pp. 27-30, October 1992.

[11] J. E. Gillott, and H. Wang, "Improved control of alkali-silica reaction by combined use of admixtures" Cement and Concrete Research, vol. 23(4), pp. 973-980, June 1993.

[12] FAOSTAT (Food and Agriculture Organization of The United Nations Statistics Division) (2011) Crops production: Economic and Social Development Department, Rome, Italy.

[13] ICAR (Indian Council of Agricultural Research) Statistics (2011) Sugarcane Breeding Institute, Coimbatore, India.

[14] IS 383, Specification for coarse and fine aggregates from natural sources for concrete, Bureau of Indian Standards, India, 2002.

[15] N. Amin,"Use of bagasse ash in concrete and its impact on the strength and chloride resistivity," Journalof Materials in Civil Engineering, vol. 23(5), pp.717-720, May 2011.

[16] IS 10262, Recommended guidelines for concrete mix design, Bureau of Indian Standards, India, 2009.

[17] IS 516, Method of test for strength of concrete, Bureau of Indian Standards, India, 2004.

[18] IS 13311, Non-destructive testing of concrete-Methods of test, Part 1-Ultrasonic pulse velocity, Bureau of Indian Standards, India, 2004.

[19] IS: 2386, Methods of test for aggregates for concrete, Part VII- Alkali Aggregate Reactivity, Bureau of Indian Standardss, India, 1963. 